\section{HARE-LIP AND ITS TREATMENT.}

GILBERT B. WARBURTON, Ch.M., F.R.C.S., SENIOR SURCEON TO THE ROYAL MANCHESTER CHILDREN'S HOSPITAL.

Tris paper is based on a considerable number of cases of hare-lip which have come under my care since carly in 1920, when I was elected to the staff of the Roval Manchester Children's Hospital, and represents an attempt to set down such facts as I have bcen able to ascertain regarding the condition.

\section{ETIOLOG AND InciDence.}

As regards the cause, I have been able to find out rery little except to confirm the fact that in a certain number of cases heredity plays a part. I regret that in the carly cases I did not go fully into the family history, but for some years now I have carefully inquired of the parents as to whether any relatives have had a similar condition.

Out of 60 cases in which the history has been fully examined $I$ have been able to trace a family history in 11. In only one of these 11 cases was it the parcintin this case the father-who had a hare-lip. More commonly it was an uncle or aunt or more distant relative who had been similarly afflicted. In two cases a relative had a cleft palate but not a hare-lip, and since the two conditions are so closely associated this is ranked as a family history. Of the 11 cases with family history the relative or relatives affected were on the father's side in 7 cases, and on the mother's in 4 .

A certain number of mothers, when questioned, attributed the condition to a fright or shock during pregnancy. While somewhat sceptical about this, yet the more one inquires into these cases the less does one feel inclined to ignore the possibility of pre-natal impressions having an effect on the developing foetus. Shocks or impressions occurring in the later periods of preguancy. need not be considered, since the formation of the $l_{i p}$ is completed at the eighth week of intranterine life.

The histories of some of the cases where the mother has attributed the condition to a shork are perhaps worth mentioning.

1. In the ease of a second child with no family history, the mother attributed the hare-lip to a fright at about two months caused by a dog jumping at her and banging her in the abdomen.

2. In the case of another second child with no family history, tho mother told me that when she was between one and two months pregnant a man fell in a fit before her and cut his lip.

3. Hare-lip and cleft palate occurred in a first child, with a family. history of cleft palate on the mother's side, but not of hare-lip. I am told that in the early montlis of pregnancy the mother worried a great deal in silence whether the baby would be born with hare-lip and cleft palate; when sl:e was told that it had both she expressed no surprisc.

T have heard of other cases where the mother has been quite convinced that her baly would be born with a hare-lip, and this has afterwards come about.

4. In the case of a second child with no family history, a cock jumped on the mother's neck at about two months, and pecked her.

5. In her first pregnancy another mother was eonstantly seeing two children with hare-lips who lived near to her. The child was born wilh a hare-lip, and there was no family history.

6. A second child was born to a woman whose brother had a lare-lip and cleft palate and died in infancy, but the mother did not remember him. All the time she was pregnant she was constantly meeting a baby with hare-lip, and could not get the thought of it out of her mind.

7. A third child with no "significant family history was born with a cleft palate but no hare-lip. The other children were normal. In this child there was an incomplete cleft palate; before and during the mother's pregnancy with it she had a maid with an incomplete cleft palate which was not operated on. When the child was born it was found that it had about the same degrec of eleft palate fis the maid.

I am inclined to think that there must be a family history in many more cases than we can obtain it in. A considerable number of penple get out of touch with their relatives, and know hut little of their family histories.

In only one case have I met with two children in the same family with hare-lip. A second child with no family history had a left complete hare-lip and cleft palate, the first child having been normal. The third child was normal, but the fourth was born with a left incomplete hare-lip though with no cleft palate.

With reference to sex, the condition is much more common in males than in females. Out of 86 of my own cases which I have been able to trace 54 were in males and 32 in females. In this particular series of cases the proportions as regards sex are probably about the average, as I find that during the years 1922-28 inclusive there were admitted to the Royal Manchester Children's Hospital 253 patients with hare-lip, and of these 166 were males and 87 females. Both these groups of figures show that the condition is nearly twice as commou in the male sex as in the female.

It is sometimes stated in textbooks that the condition is commonly associated with other congenital deformities, but, apart from its frequent association with cleft palate, this has not been my experience. Occasionally, howerer, we do find other deformities, such as talipes or naevi, and one of my cases of double hare-lip and cleft palate had at least six other congenital deformities; this; however, is quite exceptional.

My early impressions were that it was usually the first child of a family which was born with hare-lip, but on investigation this has proved to be erroneous, as out of 62 cases in which I have gone fully into this question I find that the condition was a little more common in the second child. The distribution of these 62 cases is as follows:

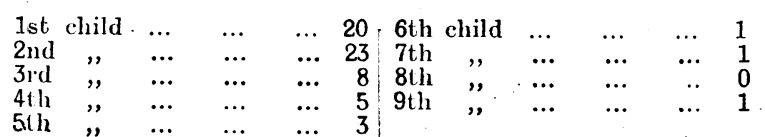

We find the deformity to be much more common in the first two children, although occurring in any child in tho family, but much less frequently in later children. At the same time we must remember that small families in many grades of societ are more common than large ones, and, in addition, many parents having had a child born with a hare-lip or other deformity will purposely limit their family in case the other children should be brought into the world with a similar handicap.

The types met with have been the usual ones: single incomplete; single complete; double incomplete; double complete; double incomplete on one side, but complete on the other side.

I have had no case of median hare-lip; the condition is very much more common on the left side than on the right. A complete hare-lip is usually associated with a cleft palate, either a cleft in the alveolus or a complete cleft in the hard and soft palates. I have come across one case with a complete (double) hare-lip with prominent displaced premaxilla causing a cleft of the anterior end of the hard palate, but with the remaining portions of the hard and soft palate normally fused. This type is rare; there is a drawing of an infantile skull showing a similar condition in Berry and Jegg's book on hare-lip and cleft palate (Fig. 13, p. 13).

In the incomplete varicties of hare-lip the deformity is usually not very serere and is generally easily remedied at operation. In some of the cases of double complete hare-lip the deformity is rery marked; the central part of the lip and the premaxilla project forward in almost a horizontal direction from the tip of the nose, and this gires rise to what is little less than a hidesus deformity.

\section{Treatment.}

Fecding and Pre-operative Details.

One of the main difficulties before operation is the question of feeding. In the serere cases the child is unable to suckle or to take food from a bottle, especially if there is an associated cleft palate, since the food regurgitates through the space in the lip or comes out through the nose. Some children can take food from a bottle when they have been unable to suckle from the breast, particularly if the bottle is fitted with a largesized teat; many, howerer, cannot be so fed, and have to be fed with a spoon. The child is partially propped up and reclining on its side; it is then fed with a spoon into one of its cheeks. By this means the food is slowly swallowed, and the baby does not tend to regurgitate it. 
The best food is the mother's milk drawn off and given with a spoon, when it can be utilized; for various reasons this can, however, rarely be done. Failing this, it is usual to give one of the reliable artificfal foods or milk suitably prepared; it is my custom to keep a child on whatever food it has been accustomed to if it is thriving on it. Spoon feeding takes up a considerable amount of time, and is a tedious proceeding, but every effort should be made to get the child to gain in weight and to become fit for the operation, since an operation on a very debilitated child is likely to be fraught with disaster. Babies who are able to suckle at the breast should become accustomed to spoon feeding, as this will be the method used for at least several days after the operation.

It is my custom to operate on the lip before attempting to close the gap in the palate, and I usually defer the operation until the child is three months old. Some of the slighter cases can be operated on a little earlier if desired. At this age the child has generally a stronger hold on life; if it has been carefully fed it is in a much better condition to stand the operation-which in the worst cases is a serere one-than if it is operated on in the very early weeks of life. Moreover, the parts of the lip are a little larger and easier to handle.

Before the operation is performed the child should be in as perfect health as possible; it should be quite frce from colds or cough, and as a general rule be steadily gaining in weight. There should have been no recent exposure to infection of any kind.

The best time of the year to operate is in the warmer weather of spring or summer; although one does operate on these cases in the winter, I certainly will not do so in very severe and particularly in foggy weather. It is advisable that the baby should be in the hospital or the nursing home for a few days to get accustomed to the new nurses, and vice versa. It is necessary to keep many of the children in hospital for a considerable period before operating, particularly those that come from poor and crowded homes. While waiting for the time of operation they are carefully fed, and every effort is made to get them to gain in weight.

If a child is steadily losing ground in spite of careful treatment, the operation is not likely to succeed or to help the child to pick up afterwards. Apart from the malformation many of these children are normal and bonny, but a certain number are puny and will not come on however much care is taken of them. If, in spite of careful attention and feeding, the baby is steadily going downhill, I do not think it wise to operate, as I am convinced that merely closing the lip will not make any material difference to the general well-being of the infant except in very rare casés. A few babies never become fit for operation, and gradually waste away or die of some intercurrent malady in 'spite of all treatment;' these are, however, in my experience, few. I do not hesitate to postpone the operation if the child does not seem up to its normal condition, since it may be sickening for some illness. With attention to these pre-operative details the results are much more likely to be successful than if the operation is undertaken without preliminary care.

\section{Operation}

The operation I have employed in practically all my cases commenced as a modification of that which is usually described as Rose's, but which has been gradually altered. This procedure, varied a little in different patients, has enabled me to bring the parts of the lip together in all types of hare-lip that I have met with. I will mention briefly what I consider to be the most important points.

If possible the anaesthetist and surgeon should be accustomed to working together and to know each other's methods, for the anaesthetics are not easy to give. I have to thank Dr. K. B. Pinson for anaesthetizing the majority of these patients for me.

The child is anaesthetized first with ether or a mixture; this is later changed over to chloroform given by means of a Junker's inhaler. The anaesthesia, while not being rery deep, should be sufficient to keep the child perfectly still and free from movement; lightness of anaesthesia and any straining or struggling tend to increase the bleeding and to shock the patient. I prefer to have the child lying flat, with the head slightly overhanging the end of the table and supported on a rest, the surgeon standing behind. A thread stitch is placed through the tongue to control it, and to make any necessary sponging-out of the pharynx easier.

The lip is everted, and the reflection of mucous membrane is divided where it meets the alveolar margin; the soft parts of the face are then loosened from the underlying bone outwards and upwards for a considerable distance, chiefly by means of blunt dissection, and all the time keeping close to the bone. Tho ala nasi must also be separated from the bone, especially in cases where it is very flattened. The undercutting is necessary more on tho outer than on the mesial side, and the amount required depends on the width of separation of the parts of the lip. Bleeding at this stage can usually be readily stopped by means of pressure with gauze pards; when one side has been loosened a pad can be packed under it while the other side is being freed. A certain amount of blood usually finds its way into the pharynx and will require to be sponged out; this should be done with the utmost gentleness, so as not to irritate the pharynx or shock the patient. The freeing of the parts of the lip is continued on both sides until they are so thoroughly mobilized that they can be brouglit together without any tension.

The next step consists in paring the edges of the lip and shaping the flaps so that two equalized raw edges may come together. The knife is inserted at the junction of the red margin and the skin in the cleft, and the red margin is excised, sacrificing as little of the true skin as possible. When the vermilion border of the lip is reached a very short horizontal cut is made between the skin and the border so as to turn down a little flap, which is then shaped up. This is next done on the other side, taking care to get both sides equal in length. The freshening of the edges should run well into the nostril, since in closing this it is advisable to make it less than it would be normally, for invariably some dilatation takes place after the operation.

In many cases of incomplete hare-lip we find the corresponding nostril unduly large, owing to the fact that although the skin has partially fused the deeper portions of the lip have not done so. In these it is necessary to carry the incisions into the nostril, first converting the incomplete hare-lip into a complete one; when the subsequent stitching up is done the nostril is made smaller and more shapely. When the edges of the lip are pared there is sharp haemorrhage from the coronary arteries; this is checked by Smith's clamps.

The suturing is next commenced; one stitch of fine silkworm-gut is placed in the free edges of the lip and held by Spencer Wells forceps, but not tied. The next one is placed at the upper end to shape and partly close the nostril. The third stitch is put in at the junction of the red margin of the lip with the skin, as it is most important to see that this line comes into accurate apposition on both sides. About two more silkworm-gut stitches are passed deeply into both sides of the lip and held in forceps. When all of the sutures have been placed the one at the free edge is tied; next the upper one at the margin of the nostril; thirdly, the one apposing the red margin; and finally those in between, bringing the edges into apposition. One or two fine horse-hair sutures may be required superficially to secure accurate skin approxim: tion. A few catgut stitches are put in on the inner side of the lip, traction on the lowest suture causing its evertion and enabling these to be put in. These sutures, in addition to helping to close the gap in the lip, prevent food from getting into it and aiso, by restoring the continuity of the mucous membrane, prevent any fusing of the inner side of the lip with the aveolar margin, thus finally leaving a free and mobile lip.

The foregoing description applies chiefly to unilateral cases, but in those of double complete hare-lip there is the further complication of the protruding pre-maxilla, which may stick out like a proboscis. I do not think the premaxilla should ever be removed, and personally have never excised it. In cases where it has been taken away there is marked flattening of tise upper lip and narrowing from side to side. 
In double complete hare-lip the central portion of the lip is separated by dissection from the underlving bone, and if the pre-maxilla is very prominent it is gently foreed back by pressure so as to lie between the maxillae. The edges of the central portion of the lip are pared until it is V-shaped. All the red margin is removed, as no attempt is made to incorporate it in the edge of the newly constructed lip; it is finally placed between the outer parts of the lip, and the point of the " $\mathrm{V}$ " lies somewhere about half-way up the lip. In double complete hare-lip the lateral parts have to be very widely mobilized so as to bring them across the pre-maxilla without undue tension. 'The steady pressnre of the newly mited lip gradually forces the pre-maxilla backwards.

In all cases the lip is, if possible, made a little longer from above kownwards than one wishes it to be finally, since a certain amount of contraction in the scar and subsequent shortening will take place. It is often wise to allow a little protrusion of the red margin almost in the form of a papilla to be present when the operation is completed, as this will later contract, and tends to prevent the notching of the lip which is sometimes seen.

When the operation is completed the parts are cleansed, and either dusted with dry boric powder or lightly painted over with tincture of iodine, no dressing bring applied.

\section{Post-operative Treatment.}

After the oprration the child is kept warm and out of draughts, and every effort is made to prevent it from getting " "hestr," or wtching a cold and dereloping a rough. It should be prevented from cring if possible, since this would make the stitches tend to cut into the lip. Usually a small dose of nepenthe is necessary when the child is coming round from the anaesthetic, and the elbows are splinted to prevent the hands being applied to the mouth. There is usually a post-operative rise of temperature to $100^{\circ}$, or it may go higher to $101^{\circ} \mathrm{or}$ $102^{\circ}$; usually this rapidly subsides and comes down to normal. Feeding after the operation is by means of a spoon, and the lip is kept dry and clean.

In the majority of cases healing is complete in about seven days from the operation; the sutures are taken out, some on the fifth day, and the remainder about seven days after the operation. In only one of my cases, and this an early one, did the lip break down almost (ompletely. The child had a complete double hare-lip, and at the operation the flaps were tight and came together under tension; as the sutures were cutting into the lip they were remored in a few days by the ward sister. The left side held, but the right side gave way. A second operation six months later was again : unsuecossul, and before another attempt.could be made the infant dereloped some chest condition, probably pneumonia; at home, and died.

The scar at first is distinct, but as time gons on it becomes whiter and much less noticenble.

Altogether $\mathbf{I}$ have performed the operation on 82 patients including two who had been operated on elsewhere. In one there was a complete single hare-lip which had broken down from end to end; the other had a right incomplete and left complete hare-lip and had been operated on twice previonsly; a very small portion of the right side was holding, the left having broken down completelv. In this case there was a very wide gap in the lip, and rery little tissue left to work with. By means of extensive undercutting I was able to get the parts together, and firm union followed both in this and in the previous case.

\section{Montality.}

In this series I have had five post-operative denths; I consider this death rate too high. There is sure to be a certain death rate, since a fairly, severe operation is being inflicted on a very young child, and, however careful we may be, some of these infints will devolop post-operative pneumonia.

The draths wore as follows, and, as will be secn, two occurred in my very carly cases.

1. A bad double complete hare-lip and the sixth case in the series; operation July 61h, 1921. The patient liorl on the operating: table just as the operation was completed. Probably the cperation took a long time, and towards its termination the ehild became pale and died of bcart. failure in spite of atlempls to resuritate it. This death I regard as purely due to operative shock.

2. Double hare-lip; operation September 21st, 1921. At the termination of the operation the patient was noticed to be w... collapsed. He recovered for a time, but two dars later died from heart failure. A post-mortem examination revealed a patent foramen ovale in the heart, and so death at an carly age wits innvitable.

3. Ieft incomplete hare-lip; opcration on May 10th, 1924. The patient survived the operation, and was well for sereral dars; unfortunatcly she then developed enteritis, and died nine dass after the operation from this cause.

4. Left complete hare-lip; operation on Apvil 16th, 1927. The infant afterwards developed broncho-pneumonia, and lied in three days.

5. Right incomplete harc-lip; opcration February 91h, 1929. A sell of rery severe weather set in after the operation; the chilit developed pueamonia four days later, and died two days afterwards.

The last 59 ases have been operated on with only two deaths, both from broncho-pneumonia. This shows a distinct improvement on the earlier series, and with more experience in operative technique and after-treatment still further improvement may be expected.

Points which have particularly interested me in lowking oret these cases have been:

1. The great preponderance of the condition in males.

2. The fact that, in the cases which have come umice my are, it is most common in the second child.

3. The great rarity of more than one child in a l:mily boing afferted.

4. The distinct tendency in a considerable perention in cun in familios. My personal view is, that if the family history could be more fully investigated we should find a history in a larger nmmber than at first appears to be the case. It is rurious that it is so rarely one of the parents who has had a similar condition, but more of ten an aunt or uncle, or more distant relation.

5. The possibility of the effects of pre-natal impressions in the first few months on the developing foctur. Prisonally, I feel forced to the conclusion that there must he something in this. There may be, in addition, a inliaily. histors, but $I \mathrm{am}$ inclined to think that any pomerime about this partienlar deformity on the part of the mother, or coming ints constant contact with others who $h_{i a r}$ it, may infurnce the foetus in its earliest stages.

\section{EXCRETION UROGRAPHY.}

A Preliminary Sote on a New Method of Radinlogical Inemenstuation of the Urinary Tract.*

BY

KEN NETH. HERITAGE, M.B., B.S., F.R.C.S.lig., RESTDENT MEDICAL OFFICER, MILLER GENFRAT HOSPITAl; AND

R. OCIFIR WARD, M.Ch.Oxon., F.R.C.S.T.Ya,

SIRGEON IN CHARGE OF GENITO-URINART DEPARTMENT, MHLLRR General hospital.

(With Special Ilate.)

THE radiological demonstration of the hollow riscera by filling the lumen with opaque medium is a methid thi:t has found wide application in surgery ; in fact, it "an be assumed that there are few cavities or potential (aritic's which remain beyond the scope of this method of examination. Taken collectively, the accepted methorls fall into two main groups. First, the artificial filling of the lumen with a radiographically demonstrable medium introducd from without, frequently under a small head of pressure. This is seen in the present method of pyelography via the ureteric catheter, which has marked so great an adrance in renal diagnosis. The second group depends on the production of a radio-apaque secretion to demonstrate the excretory passages of the gland. While imposing rery definite limitations in application, and difficulty in finding a suitable non-toxic yet selective excretory substance, this method offers an adrantage in showing a pieture untouched by instrumentation. Grahan's epoch-making work on cholerystography, emploring an organic combination of a (holagogue (phenolphthalein) with a rarlio-opaque halogen, * Submitted for publication on Mareh 3 rd, 1930 